\title{
Exploring the feasibility of development of nanomaterial-based microwave absorbers
}

\author{
Surekha Rani ${ }^{1} \cdot$ Anupma Marwaha ${ }^{1} \cdot$ Sanjay Marwaha ${ }^{1}$
}

Received: 17 March 2018 / Accepted: 30 October 2018 / Published online: 7 November 2018

(c) The Author(s) 2018

\begin{abstract}
Advancement in the use of microwave electronics by the wireless devices, networks' server and switches, wireless antenna systems, and mobile phone base station potentially increased the radio-frequency interference. Effective elimination of this electromagnetic pollution is very necessary for proper working of electronic equipments. Microwave absorbers serve the above purpose leading to have enormous commercial and defence applications, for antenna shielding and laboratory testing of antenna. Researchers are, therefore, paying much attention on the study and fabrication of different materials and their shapes so as to use them as an absorber which ideally exhibits properties such as (1) strong absorption; (2) minimize the reflection of microwaves at air to absorber interface; (3) broader bandwidth; (4) low weight and thickness; (5) ignition at very high temperature; (6) frequency tunability; and (7) transparent and cost effective. In this paper, absorber designs based on materials and geometries proposed by number of researchers have been extensively reviewed. The preamble presented here can be explored to design novel absorbers combining material and geometry-based designs for enhanced performance to meet the future challenges.
\end{abstract}

Keywords Radar-absorbing materials $\cdot$ Microwave-absorbing geometry $\cdot$ Nanocomposites $\cdot$ Permeability $\cdot$ Permittivity $\cdot$ Absorption bandwidth

\section{Introduction}

Microwave absorbers have been observed to be used in wireless communication for suppression of interference. In case of radar arrays, placing an absorbing device between array elements can enhance directivity and suppression of side lobes. In addition, to build an anechoic chambers which are used for laboratory testing of an antenna, monostatic, and bistatic radar cross section patterns or any other microwave system, a component must required having capability of virtually converting a closed room laboratory into a free space, where the reflections from side walls of laboratory are nil [1-5]. In addition to above, because of the rapid

Surekha Rani

surekhagarg9@gmail.com

Anupma Marwaha

marwaha_anupma@yahoo.co.in

Sanjay Marwaha

marwaha_sanjay@yahoo.co.in

1 SLIET, Sangrur, Longowal, India development in stealth technology for concealment of an object from radar detection, extensive uses of electronic devices, development of microwave absorbers becomes hot subject among researchers [6, 7].

In different literatures, various techniques have been discussed to make such absorbers which can fulfil above requirements up to desired extent. In broad sense, the absorbers proposed by researcher are either material based or geometry based. Material-based absorber is basically a frequency-selective surface [8-10]; having high dielectric or magnetic losses, specially designed to reflect, transmit, or absorb electromagnetic waves depends on frequency selected [11]. These absorbers are very simple, cost effective, flexible, and able to withstand extreme temperature ( -65 to $250{ }^{\circ} \mathrm{F}$ ) and environmental conditions such as foam, epoxy resin, plastics, or elastomers [12-16]. Geometry-based absorbers can further enhance the absorption properties of a simple material by moulding it into a resonance structure or cavity which moves resonant frequencies back and forth and absorb them in terms of heat. These geometries such as dielectric cavities, pyramidal structures, geometric tapering, and Jerusalem cross with added loads are proposed so as 
to achieve the desired properties as per applications [17, 18]. The main motive of this review is not just to collect the absorption properties of above-mentioned absorbers, but also gather their electromagnetic properties such as dielectric constant, electric, and magnetic loss tangents which are very necessary to use them for electromagnetic pollution elimination or for side lobe suppression of antenna arrays.

\section{Material-based absorbers}

Material-based absorber works on the realization of Maxwell's equations related to absorption stating that a material having equal electrical permittivity and magnetic permeability should have no interface reflection at normal incident because of matching the impedance with free space. Thickness of such material can be controlled to obtain adequate attenuation to electromagnetic waves up to desired level. Moreover, if relative permittivity or permeability of the material is high, it causes high electric or magnetic loss tangents, thus proving to be a good absorber [19, 20]. Hence, material-based absorbers can be broadly categorized into magnetic materials and dielectric materials depending on whether permeability or permittivity is high, respectively. Researchers found a class of magnetic materials known as ferrites which has significantly better absorption capabilities than others in that regard [21-23]. Similarly, in dielectric materials also, there are a number of advanced nanomaterials and metamaterials or the composites of both proposed by a number of authors to meet the application needs.

\section{Magnetic composites}

Magnetic composites are a class of composites, whose properties can be manipulated using magnetic fields and to use them as absorber relative permeability $(\mu)$ and magnetic losses are encountered [24, 25]. These are the combinations of two or more composites in which one will be ferrites [26]. Ferrites are non-conductive ferromagnetic compounds of ceramic derived from iron oxide mixed with other metal oxides, having the cubic crystal structure [27-29]. These are one of the earliest materials [30,31] used as radar-absorbing material, while in some ferrites, the relative permittivity and permeability varied so rapidly with frequency that their utilization becomes limited to narrowband; therefore, different ferrite composites were later presented in the literature [32, 33] which were able to provide $10-35 \mathrm{~dB}$ reflection losses at $\mathrm{S}, \mathrm{X}$, and $\mathrm{Ku}$ frequency bands. Since ferrites are inorganic compounds, they do not burn easily when incident energy is absorbed in terms of heat and are capable to dissipate incident power up to $20 \mathrm{~W}$ per square inch [34, 35]. Ferrites are also used as filler materials to enhance magnetic losses of a material designed for low-frequency requirements
[36]. Qin et al. investigated absorption properties of W-type barium cobalt ferrite powder doped with MnZn composites of $\mathrm{Ba}(\mathrm{MnZn})_{x} \mathrm{Co}_{(1-x)} \mathrm{Fe}_{16} \mathrm{O}_{27}(x=0.1,0.2,0.3,0.4$, and 0.5) for frequency range of 2-18 GHz. Absorption capabilities of the proposed absorber primarily based upon magnetic losses due to magnetization relaxation, hysteresis loss, and domain wall resonance. Author prepared the $2.8 \mathrm{~mm}$-thick sample which caused $-40.7 \mathrm{~dB}$ reflection loss at a frequency of 7.3 $\mathrm{GHz}$ and $6.6 \mathrm{GHz}$ effective $-10 \mathrm{~dB}$ bandwidth, where reflection losses were less than $-10 \mathrm{~dB}$. It concluded that $x=0.4$ is the optimum value of doping concentration, at which maximum reflection loss was obtained [37].

Liu et al. analyzed the absorption properties of singleand double-layered carbonyl iron (CI) and $\mathrm{CoFe}_{2} \mathrm{O}_{4}$ ferrite samples for frequency range from 2 to $18 \mathrm{GHz}$. Double-layer absorber showed much better absorption capabilities which consists of powdered $\mathrm{Cl}$ layer as absorbing layer whose permittivity varies between 21.9 and 19.7 and $\mathrm{CoFe}_{2} \mathrm{O}_{4}$ ferrite layer as matching layer having 3.7 constant permittivity backed by metal plate. Maximum reflection loss of $-38.2 \mathrm{~dB}$ occurred at $11.8 \mathrm{GHz}$ frequency when thickness of matching and absorbing layer was $2.4 \mathrm{~mm}$ and $0.5 \mathrm{~mm}$, respectively. Authors concluded that effective bandwidth of the proposed sample covered both $\mathrm{X}$ and Ku bands [38].

$\mathrm{Li}$ et al. combined the ferrites named X4D (a Garnet ferrite) and metasurface to obtain absorption tunability from controlling external magnetic field for frequency range from 0.2 to $7.6 \mathrm{GHz}$. Dielectric constant of ferrites is 12.8 with a loss tangent of 0.0002 having $80 \mathrm{~mm} \times 40 \mathrm{~mm}$ size with thickness $1 \mathrm{~mm}$. With the help of CST simulation, authors showed the variation of absorption peaks by varying external magnetic field ranging between 10 and 2600 Oe. From simulation as well as experimentally, it concluded that at 10 Oe magnetic fields, absorption peak obtained at $3.2 \mathrm{GHz}$ and shifted to $7.5 \mathrm{GHz}$ at 2600 Oe field [39].

In addition to the various ferrite composites, further composites have been proposed by the researchers by merging the materials in which one has high permittivity, while other has high permeability, so that absorption capabilities further enhanced. Vinayasree et al. mixed the magnetic and dielectric material by blending different percentage of strontium ferrites in carbon black nitrile rubber to enhance magnetic losses in the sample for S-band (2-4 GHz) and X-band (8-12 GHz) applications. With the 50 parts per hundred concentration of strontium ferrites in carbon rubber (50 CBSrF), dielectric constant raised to 14 . Author demonstrated the reflection loss curves at different sample thicknesses and concentrations and concluded that maximum $-35 \mathrm{~dB}$ reflection loss occurred at $10.9 \mathrm{GHz}$ with $6.5 \mathrm{~mm}$ thickness and 30 CBSrF [40].

Similar to above idea, Teber et al. also proposed to blend the magnetic and dielectric materials to enhance absorbing properties which have weak attenuation capabilities 
by themselves. A sample of multiwalled carbon nanotubes (MWCNT) blended with manganese and zinc spinel ferrites $\left[\mathrm{Mn}_{1-x} \mathrm{Zn}_{x} \mathrm{Fe}_{2} \mathrm{O}_{4}(x=0.0\right.$ and 1.0)] was synthesized with a binder matrix of paraffin of $3 \mathrm{~mm}$ thickness. Results showed the reflection loss of $-56 \mathrm{~dB}$ at $11.41 \mathrm{GHz}$ for doping concentration $x=0.0$ with $3.38 \mathrm{GHz}$ effective bandwidth, where reflection loss is less than $-20 \mathrm{~dB}$ [41].

Gogoi et al. determined absorption capabilities of silicone rubber loaded with nanosize strontium ferrite $\left(\mathrm{SrFe}_{12} \mathrm{O}_{19}\right)$ at different weight percentages ranging from 20 to $60 \mathrm{wt} \%$ for $\mathrm{X}$-band application. The results showed $-15.4 \mathrm{~dB}$ reflection loss $9.6 \mathrm{GHz}$ frequency when sample thickness was $3.5 \mathrm{~mm}$ and weight percentage was $60 \mathrm{wt} \%$ and $-10 \mathrm{~dB}$ effective bandwidth for 8.2-12.4 GHz band [42].

Researchers have also concentrated on preparing ferrites composites with some advanced nanomaterials, so that a very lightweight, thin absorber can be proposed. Therefore, Zhao et al. presented absorption properties of graphenecoated $\mathrm{Fe}$ nanocomposites based on the principle that between metal and graphene, interfacial electronic interaction allows to transfer charge, thus can alter the electronic properties of graphene which introduced some novel electrical and magnetic properties in metal-graphene heterostructure. Reflection loss measurements are dome by pressing the samples in a hollow cylindrical waveguide with outer and inner dimensions as $7 \mathrm{~mm}$ and $3 \mathrm{~mm}$, respectively. Authors concluded that the samples of Fe particles having thickness between 1 and $4 \mathrm{~mm}$ have very low reflection losses which do not go beyond $-6 \mathrm{~dB}$, but when the same samples are coated with graphene, then reflection loss goes up to $-45 \mathrm{~dB}$ at $7.1 \mathrm{GHz}$ [43].

\section{Dielectric nanocomposites}

In dielectric nanocomposites, two or more materials are combined to enhance and control the relative permittivity of resultant material on application of external electric field $[44,45]$. Metamaterials are also a part of dielectric nanocomposites which were greatly explored in the end of nineteenth century to manipulate the electromagnetic waves $[26,46]$. They are artificial or manmade materials fabricated from nanostructured composites or nanocomposites specially designed to miniaturize existing absorbers, wider adaptability, and increased effectiveness by enhancing its dielectric constants. The most prominent examples of dielectric nanocomposites which are used to build metamaterials are quantum dots, graphene, metallic nanospheres or nanorods, multiwalled carbon nanotubes, and semiconductor nanowires. Absorption capabilities of these nanocompositebased absorbers have been reviewed as below.

Bhattacharya et al. introduced Graphene and Multiwall Carbon Nanotubes (MWCNT) as a radar-absorbing material by preparing two samples of Thermoplastic
Polyurethane Matrix (TPU) which are 10\% loaded with graphene and MWCNT. Thicknesses of the samples are maintained to $2 \mathrm{~mm}$ suitable for applied frequency in $\mathrm{X}$ band (8.2-12.4 GHz). Authors have shown the permittivity and permeability graphs of both samples and concluded that particularly, in X-band region, absorption capabilities of graphene are much better than the MWCNT [47].

Zhang et al. investigated the absorption properties of graphene-CdS (cadmium sulphide) with the help of transmission electron microscope, $\mathrm{X}$-ray diffraction, and the coaxial line method. Authors have developed various samples by facile hydrothermal approach, whose thicknesses are adjusted between 2 and $5 \mathrm{~mm}$ for the frequency range of $2-18 \mathrm{GHz}$. From experimental demonstration, it is concluded that reflection loss is enhanced to $-48.4 \mathrm{~dB}$ at $9.95 \mathrm{GHz}$ for the thickness of $3.3 \mathrm{~mm}$ and $12.8 \mathrm{GHz}$ effective absorption bandwidth is obtained at frequency range from 5.2 to $18 \mathrm{GHz}$ [48].

Batrakov et al. present an efficient electromagnetic field absorber consists of optimum number of graphene planes which are separated by thin polymer spacers particularly designed for $\mathrm{Ka}$ band $(26.5-40 \mathrm{GHz})$. Graphene which is deposited on quartz (fused silica) substrate by chemical vapour deposition technique is sandwiched between PMMA layers. The permittivity of silica substrate is taken as 3.7, and the overall thickness of graphene/PMMA six layered is $4.2 \mu \mathrm{m}$ and provides $50 \%$ absorption at $30 \mathrm{GHz}$ frequency. Authors both experimentally and theoretically concluded that the absorption is monotonically increased as the number of layers increased up to six layers, after that absorption decreases with increasing number of layers [49].

Barbosa et al. experimentally prove the excellent microwave-absorbing property of graphene using polyurethane as substrate. The sample is characterized with Raman spectrometer, optical microscope, and vectorial network analyzer. On the basis of experimental results, authors concluded that graphene can effectively replace the conventional microwave-absorbing materials due to its unique characteristics of flexibility, tunability, transparency, lightweight, costeffectiveness, and RF shielding [50].

$\mathrm{Wu}$ et al. realized optically transparent broadband absorber operating in millimetre band made by stacking a few layers of graphene on the quartz substrate backed by a metal ground plane. In this paper, authors have controlled the resistivity of the graphene sheets by controlling the chemical potential which depends on external biasing. Authors concluded that as the chemical potential increases from 0 to $3 \mathrm{eV}$, the reflection coefficient decreases and absorption increases. In addition, at constant chemical potential, by increasing number of graphene layers, absorption increases but at cost of transparency. Similarly, if a few layers of graphene are arranged in $z$ direction, then the absorber covers a broad range of frequency, i.e., from 110 to $170 \mathrm{GHz}$ because 
of the presence of multiabsorption peaks. However, such absorber is not very efficient for TE polarized wave when incident angle is more than $300^{\circ}$ [51].

Savi et al. introduced the microwave-absorbing properties of epoxy resin loaded with different weight percentages of multi-walled carbon nanotubes (MWCNT) in the frequency range of 3-18 GHz. Samples of single-layer epoxy resin with different MWCNT concentrations $(0.5,1,3$, and $5 \mathrm{wt} \%)$ backed by a metal plate were prepared having diameter and thickness as $20 \mathrm{~mm}$ and $15 \mathrm{~mm}$, respectively, to measure absorption coefficient by cylindrical waveguide method, as shown in Fig. 1.

Authors concluded that by increasing weight percentage of MWCNT, absorption increases and at $5 \mathrm{wt} \%$, value of absorption coefficient is $-18 \mathrm{~dB}$ at $8 \mathrm{GHz}$. The weight percentage cannot be increased beyond 5 , because sample no longer remains homogeneous [52].

$\mathrm{Wu}$ et al. presented the microwave absorption and nearfield radiation behaviour of monolayer as well as few layers of large-area graphene obtained by chemical vapour deposition method especially for $\mathrm{C}$ and $\mathrm{X}$ bands. The absorption coefficient and return loss are verified by non-contact microwave cavity measurements and four-probe DC resistivity method.

Authors used microwave cavity absorption technique for measuring the sheet resistance of graphene. The cylindrical cavity is excited by a pair of probes, where graphenebearing quartz substrate placed at the base of cavity. Thus, graphene-bearing quartz substrate started behaving as Salisbury screen-like absorber. For the multilayer graphene, by increasing the number of layers of graphene, conductivity increases which reduces the sheet resistance. As graphene behaves like a lossy dielectric, the quality factor becomes proportional to the sheet resistance. Hence, increasing the layers of graphene, quality factor and resonance peak decrease.

From near-field measurements, it is revealed that radiation does not enhance by increasing layers on lossy dielectric region instead absorption increases, therefore, proved as good absorber for large component shielding [53].
Balci et al. presented the microwave-absorbing, electrically tunable capacitor using large-area graphene electrodes separated by $50-\mathrm{mm}$-thick spacer filled with ionic liquid $\mathrm{Tf}_{2} \mathrm{~N}$, which works as an electrolyte. Authors concluded that by changing the voltage of capacitor from 0 to $3.5 \mathrm{~V}$, charge density inside capacitor varies which effects the absorption, transmission and reflection properties of capacitor thus works as narrowband but tunable microwave absorber at $10.5 \mathrm{GHz}$ frequency [54].

Xin et al. prepared ternary nanocomposite material of graphene oxide (GO)/polyaniline nanocomposite (PANI)/ $\mathrm{Fe}_{3} \mathrm{O}_{4}$ particles (GPF) via two-step method. In first step, by dilute polymerization, GO/PANI composites are prepared, and then, GO/PANI/ $/ \mathrm{Fe}_{3} \mathrm{O}_{4}$ is synthesized using coprecipitation method with thickness of whole sample of $2 \mathrm{~mm}$. Authors experimentally demonstrated that maximum reflection loss of $\mathrm{GO} / \mathrm{PANI} / \mathrm{Fe}_{3} \mathrm{O}_{4}$ sample is up to $-27 \mathrm{~dB}$ at $14 \mathrm{GHz}$, which can be further increased by increasing thickness up to $4 \mathrm{~mm}$ because of better impedance matching and concluded that the absorption coefficient of presented sample is higher than individual GO, PANI, and GO/PANI samples [55].

Zhang et al. explored the microwave absorption properties of ultralight graphene form at 30,60, and 90\% compressive strain represented as GF-30, GF-60, and GF-90. Various GF samples of different dimensions are fabricated according to working frequency range, i.e., for measurements in the frequency band of $2-18$ and $26.5-40 \mathrm{GHz}$, and cubic container of GF is cut with dimension $180 \times 180 \times 15 \mathrm{~mm}$. Authors concluded that with increasing strain, permittivity of GF increases; therefore, at GF90 with thickness of $1 \mathrm{~mm}$, absorber has $60.5 \mathrm{GHz}$ effective bandwidth which includes the whole bands of $\mathrm{X}(8-12 \mathrm{GHz}), \mathrm{Ku}(12-18 \mathrm{GHz}), \mathrm{Ka}$ $(26.5-40 \mathrm{GHz}), \mathrm{W}(75-110 \mathrm{GHz})$, and half of the $\mathrm{C}$ band (4-8 GHz) [56].

Das et al. prepared three samples based on epoxy resin and loaded with graphene oxide, $\mathrm{FeCoB}$ alloy, and $\mathrm{FeCoB}$ coated graphene oxide, each with $30 \%$ weight ratio particularly for the X-band (8-12 GHz) applications. With help of vector network analyser, permittivity of $\mathrm{GO}, \mathrm{FeCoB}$, and
Fig. 1 a, b Measurement setup and sample compared with one euro coin [52]
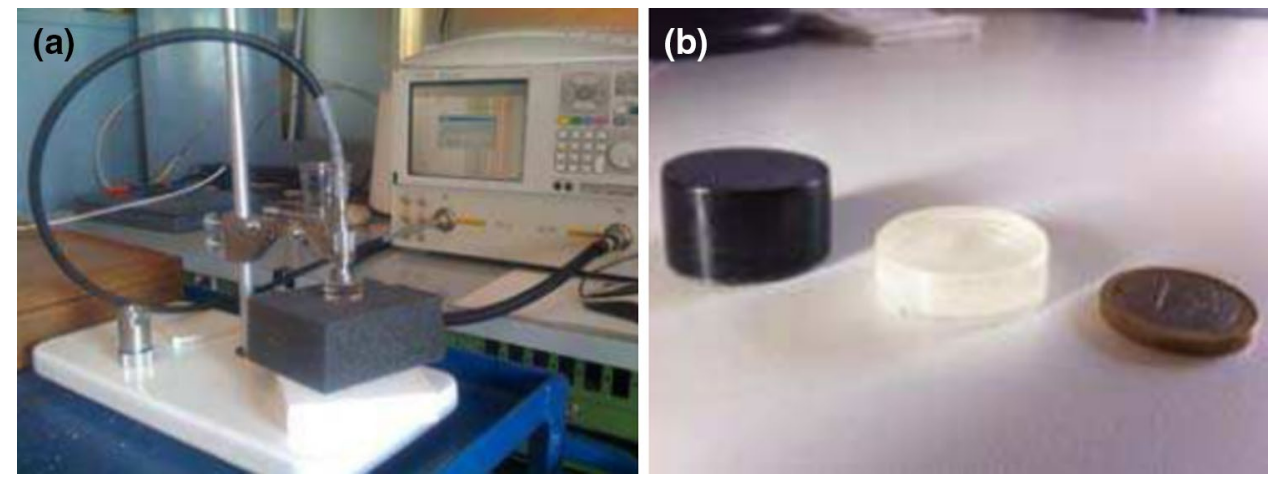
FeCoB-coated GO composite is measured close to 2, 15, and 17.5 , respectively, at $11 \mathrm{GHz}$. Authors show experimentally that reflection loss value for $\mathrm{GO}$ loaded in $\mathrm{FeCoB} /$ epoxybased composite was found to be $-22.24 \mathrm{~dB}$ at $12.4 \mathrm{GHz}$ which is much better than $\mathrm{GO}$ composite and $\mathrm{FeCoB}$ alloy and having ability to absorb $95 \%$ of incident wave within $10-12.4 \mathrm{GHz}$ range, whereas for $\mathrm{FeCoB}$ alloy, its value is $95.3 \%$ at $11.67 \mathrm{GHz}$ which showed broader absorption bandwidth [57].

Luo et al. prepared reduced graphene oxide/strontium ferrite/polyaniline (R-GO/SF/PANI) ternary nanocomposites in two steps, where strontium ferrite nanoparticles were synthesized by a coprecipitation method in first step, after that using situ polymerization method, full nanocomposite sample was prepared. Electromagnetic absorption properties of the sample are measured by vector spectrum analyser within the range of $2-18 \mathrm{GHz}$. Authors concluded that sample with thickness $1.5 \mathrm{~mm}$ gives rise to the maximum reflection loss equals to $-45 \mathrm{~dB}$ at the frequency of $16.08 \mathrm{GHZ}$ with effective bandwidth $5.48 \mathrm{GHz}$ and makes it a suitable microwave-absorbing material [58].

Yi et al. used graphene as a microwave absorber by making a salisbury screen of fluorine-doped tin oxide glass, glass and monolayer graphene which act as the reflector layer, substrate, and absorbing layer, respectively. Graphene is of one atom thickness, glass is of $2.2 \mathrm{~mm}$, and FTO $300 \mathrm{~nm}$. The Salisbury screen is tested with the help of rectangular waveguide, and the same is simulated using three-dimensional simulation software and it is concluded that absorption coefficient exceeds above $95 \%$ around $15.1 \mathrm{GHz}$. In this paper, tenability property of graphene is not used which can make absorber even more efficient [59].

Rubrice et al. introduced dielectric characteristics and microwave absorption properties of epoxy resin loaded with graphene particles, where particles size varies between 3 and $15 \mu \mathrm{m}$. The effect on absorption by changing particles weight ratio between 10 and $25 \%$ has also being considered within the frequency range of $2-18 \mathrm{GHz}$. Authors concluded that by increasing working frequency, the dielectric constant has been reduced due to the relaxation phenomenon such as rotational and vibrational transitions, atomic polarization. At constant working frequency, as the particle size increases, dielectric constant increases, and thus, magnitude of absorption peaks increases. For $15 \mu \mathrm{m}$ particle size and $10 \%$ weight ratio, for $18 \mathrm{GHz}$ working frequency, the dielectric constant is measured as 20.4 and loss tangent is 0.16 [60].

Huang et al. proposed an absorber consisting of nanoflakes of graphene printed on flexible silicone substrate by preparing a conductive graphene ink using stencil-printing method particularly covering both $\mathrm{X}(8-12 \mathrm{GHz})$ and $\mathrm{Ku}(12-18 \mathrm{GHz})$ bands. Due to the flexibility of printed graphene nanoflakes, the absorber can conformably bend and can be attached to metal cylinder, thus reducing the radar cross-sectional area of the cylinder. The sample of dimensions $300 \mathrm{~mm} \times 200 \mathrm{~mm}$ was fabricated having conductivity $4.33 \times 10^{3} \mathrm{~S} / \mathrm{m}$ and attached to the cylinder having radius $5.9 \mathrm{~cm}$. Authors demonstrated experimentally that reflection coefficient is below $-30 \mathrm{~dB}$ at frequency $12.2 \mathrm{GHz}$, and effective absorption bandwidth is above 90\% from 10.4-19.7 GHz [61].

Wei et al. introduced graphene as tunable microwave absorbers, whose central frequency is tuned. Graphene tunability can be achieved easily in terms of absorption magnitude, because inherently, graphene works as tunable resistive film in $\mathrm{GHz}$ band and this resistance is changed by changing electrostatic bias. However, with this, attenuation in terms of amplitude is tuned, but central frequency remains the same.

Therefore, authors presented two approaches by which the central operating frequency of graphene can be tuned while maintaining absorption magnitude. In first approach, named "tuning surface resistance", a periodic layer of graphene is etched in terms of patches to increase the distributed capacitance. These patches behave as capacitive and resistive surface hence works as resonator for electromagnetic waves and consumes electromagnetic energy in terms of heat because of the presence of resistive surface. Therefore, resonance frequency in this approach depends upon these surface capacitances and resistances, hence obtained tunability while maintaining absorption magnitude. Using 3D full-wave simulation, authors have plotted the graphs in which by changing value of $R_{s}$ from 60 to $600 \mathrm{O}$, resonant frequency increases from 6.7 to $13.7 \mathrm{GHz}$.

The second approach, "stacking graphene metasurface", the graphene film, is transferred on the polyethylene terephthalate (PET) film and frequency is tuned discretely depending upon the number of stacking layers of PET. When the stacking layer increases, capacitance increases and resistance decreases and causes sample resonates at lower frequency. From this approach, authors have concluded that when the number of stacked layers increases from 1 to 3 , the central operating frequency occurs at 13.5, 12.9, and $12.3 \mathrm{GHz}$, respectively, but these absorption peaks can be further improved using specific microwave-absorbing geometry instead of simple stacks [62].

Xiong et al. presents equivalent circuit model to analyze the effect of chemical potential on the resonance frequency of graphene metamaterial absorber. The graphene metamaterial patches of $300 \mathrm{~nm}$ thickness are developed on silicon dielectric slab with relative permittivity 11.9. These patches are equivalent to lumped resistor capacitor circuit, whose impedance and reflection loss can be calculated analytically. Authors concluded that for chemical potential of $0.4 \mathrm{eV}$, the reflection coefficient $-21.56 \mathrm{~dB}$ occurs at $f=9.65 \mathrm{THz}$ and there is good agreement between analytical and simulated results [63]. 
Rahmanzadeh et al. utilized the plasma medium and graphene sheets for making an ultra broadband absorber structure for the frequency range of 10-100 GHz. First layer of the proposed absorber is the undoped graphene sheet acting as lossy layer followed by collisional plasma fills as second layer. After that, four undoped graphene sheets embedded between silicon dioxide as third layer. The last layer is a thin foam slab, whose EM characteristics are matched with free-space characteristics backed by a perfect electric conductor. Thickness of overall structure is $1.65 \mathrm{~cm}$. Through CST simulation and experimentally, authors concluded that at $55 \mathrm{GHz}$ frequency, the reflection loss is below $-40 \mathrm{~dB}$ which is much better than the absorbers with only plasma and graphene and absorption rate is $97 \%$ from 5 to $52 \mathrm{GHz}$ [64].

Heydari et al. synthesize the polyaniline/carbon nanotubes core/shell nanocomposite decorated with nanoparticles of ferrite and cobalt oxides, as depicted in Fig. 2. After investigation with the help of vector network analyzer, authors showed that absorption coefficient of ( $\mathrm{Fe}, \mathrm{Co})$ oxide-PANI-CNT core/shell nanocomposite increases as the percentage of (Fe, Co) nanoparticles increases from 1 to $10 \%$ in polyurethane matrix. Authors concluded that maximum reflection losses of value $-2.14 \mathrm{~dB}$ and $-7.32 \mathrm{~dB}$ occur at frequencies $9.33 \mathrm{GHz}$ and $11.97 \mathrm{GHz}$, respectively [65].

Some authors also concentrate on proposing their own metamaterials, whose permittivity, permeability, loss tangents, and physical dimensions are optimized to obtain a good absorber. Based on metamaterials approach, El-Hakim et al. introduced double-layer microwave absorbers for $\mathrm{X}$ and $\mathrm{Ku}$ bands, in which the characteristics of these two absorbing layers such as thickness, permittivity, and permeability are optimized using genetic algorithm and these optimized values are used to fabricate dual layer absorber. The first layer called the matched layer having resistance close to $377 \mathrm{O}$ is made from natural rubber loaded with 50\% ferrimagnetic powders, $6.5 \%$ graphite, and $1.5 \%$ carbon fiber. Similarly, the second layer mainly used to achieve high absorption has the rubber as host material with $45 \%$ carbon powder. Dimensions of absorber are $1.5 \mathrm{~cm} \times 1.5 \mathrm{~cm}$ and thickness $2.5 \mathrm{~mm}$ for the first layer, and $1.5 \mathrm{~mm}$ for the second one and free-space setup is used to measure the return loss. Simulation of the same model is done using HFSS. Authors concluded that reflection loss with double-layer absorber reached up to $-28.32 \mathrm{~dB}$ for normal incidence, whereas in case of oblique incidence, it is $-17 \mathrm{~dB}$ which means that incident angle greatly affects the reflection loss which is not desirable [66].
$\mathrm{Xu}$ et al. proposed the double-layer absorber samples of different thickness which is based on the $\mathrm{CoFe}_{2} \mathrm{O}_{4} / \mathrm{PANI}$ (polyaniline) composite act as matching layer and calcined $\mathrm{CoFe}_{2} \mathrm{O}_{4}$ which works as absorbing layer, synthesized by ferrite chemical oxidative polymerization of aniline for the frequency range of 2-18 GHz. Authors concluded that minimum reflection loss for the thickness of $2 \mathrm{~mm}$ is $-19.0 \mathrm{~dB}$ at $16.2 \mathrm{GHz}$, and with increase of thickness up to $2.5 \mathrm{~mm}$, centre frequency shifts to $12.8 \mathrm{GHz}$ with reflection loss value $-31.1 \mathrm{~dB}$ with $10 \mathrm{~dB}$ absorption bandwidth is $4.2 \mathrm{GHz}(13.8-18.0 \mathrm{GHz})$ [67].

The comprehensive details of various microwave absorbers based on material are enlisted in Table 1.

\section{Geometry-based absorbers}

Geometry or structured absorbers are based on principle of tapered impedance. Steadily increasing the geometry increases the impedance. Surface which faces incident wave has low impedance which goes on increasing as wave goes from front side to rarer side of the surface. This type of structure causes progressively absorbs and attenuates the em energy through ohmic loss as it propagates through absorber. These are basically resonant structures having narrowband absorption peaks, and accordingly, various researchers have the proposed number of designs of resonant structures which can be then combined in the form of array to overlap their resonance peaks to obtain wideband characters.

Bilotti et al. proposed a narrowband absorber based on split ring resonator (SRR) made from metamaterial of length $5 \mathrm{~mm}$ with a resistive sheets ( $377 \mathrm{O}$ resistance) placed in close proximity separated by free space, so as not to alter the resonance characteristics of SRR. Structure is not backed by metal plate, because it increased RCS of object at every other excluding tuned frequency. Authors simulated the model using CST, and showed $-27.5 \mathrm{~dB}$ reflected power at $2 \mathrm{GHz}$ frequency with single ring. As the number of rings increases, the resonance frequency shifts toward lower end of frequency range [68].

Yin et al. designed ultra wideband absorber by connecting multiple hyperbolic structures having different resonance peaks for $4-40 \mathrm{GHz}$ band based on principle of multiple $\lambda / 4$ resonances and the edge diffraction effect. Planer array of $4 \times 4$ size having two different width hyperbolic waveguide structures of $13 \mathrm{~mm}$ and $33 \mathrm{~mm}$ is placed on copper substrate with $34 \mathrm{~mm}$ lattice constant, as depicted in Fig. 3. Authors showed experimentally that the absorption coefficient remains near 1 for whole frequency range from 4 to $40 \mathrm{GHz}$ except two frequency dips at 5.8 and $9.5 \mathrm{GHz}$ [69].
Fig. 2 Mechanism of (Fe, Co) oxide-PANI-CNT core/shell nanocomposite formation [65]
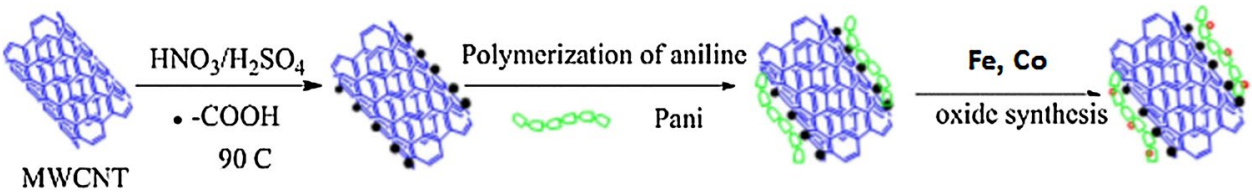


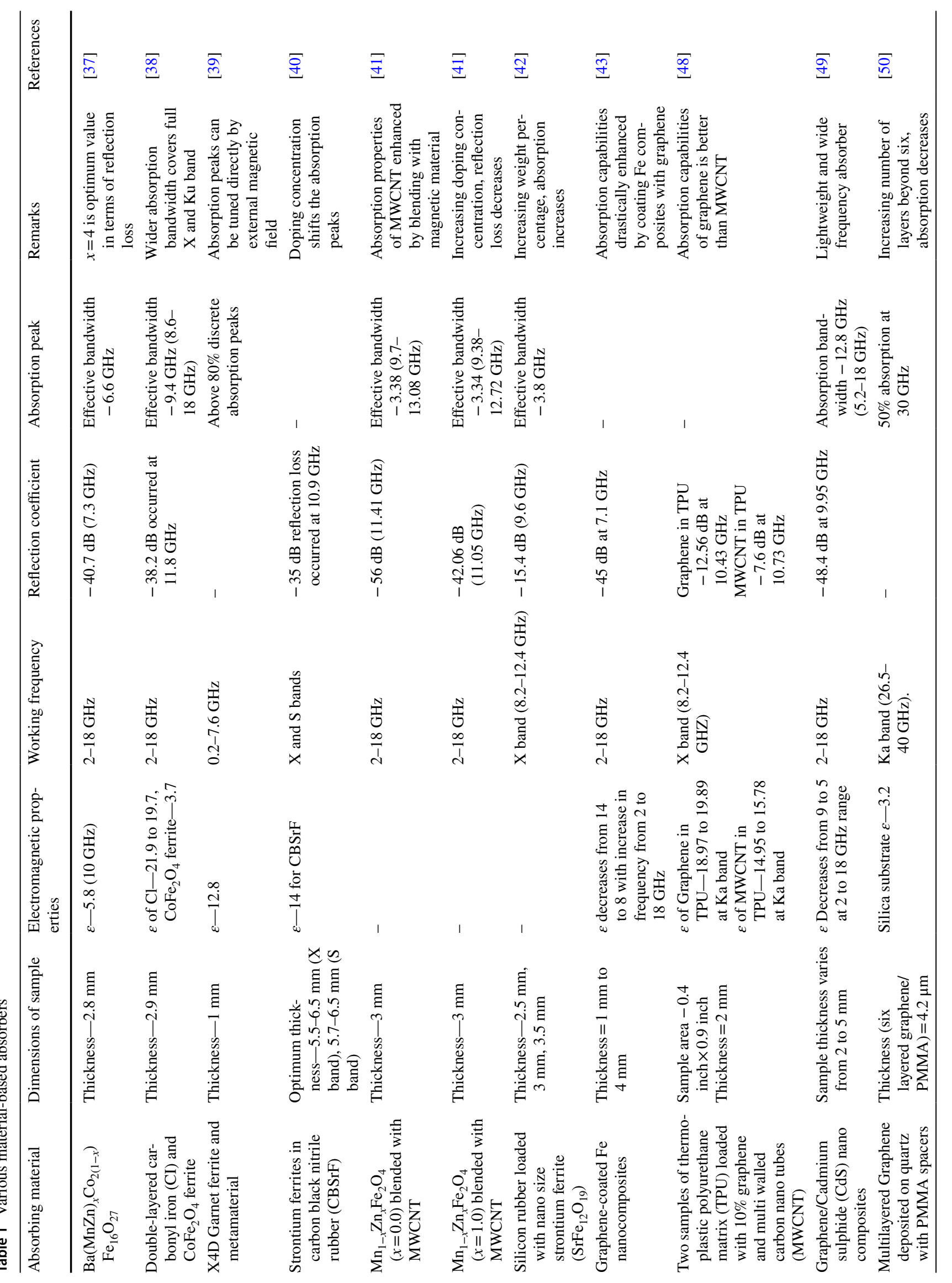




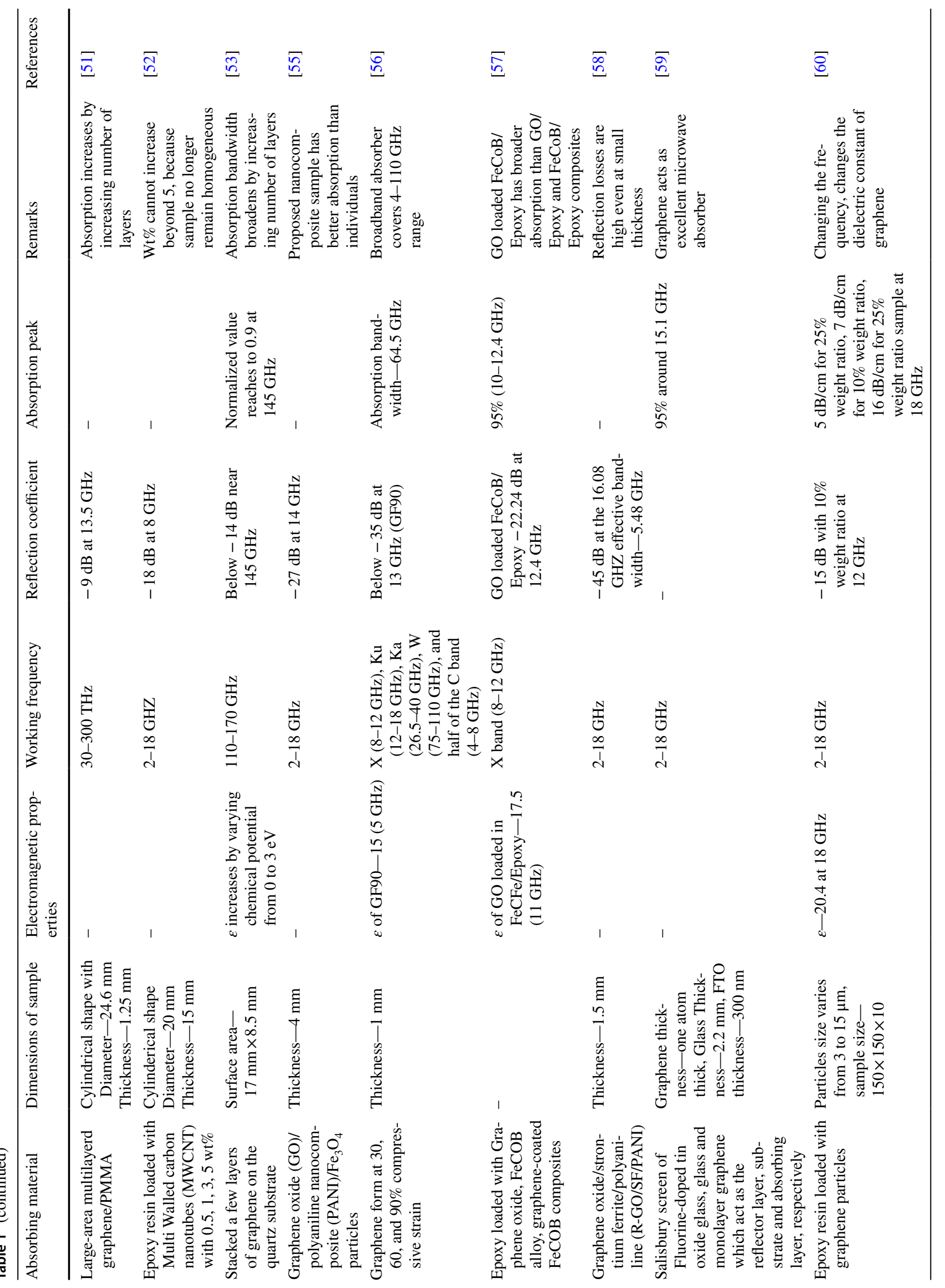




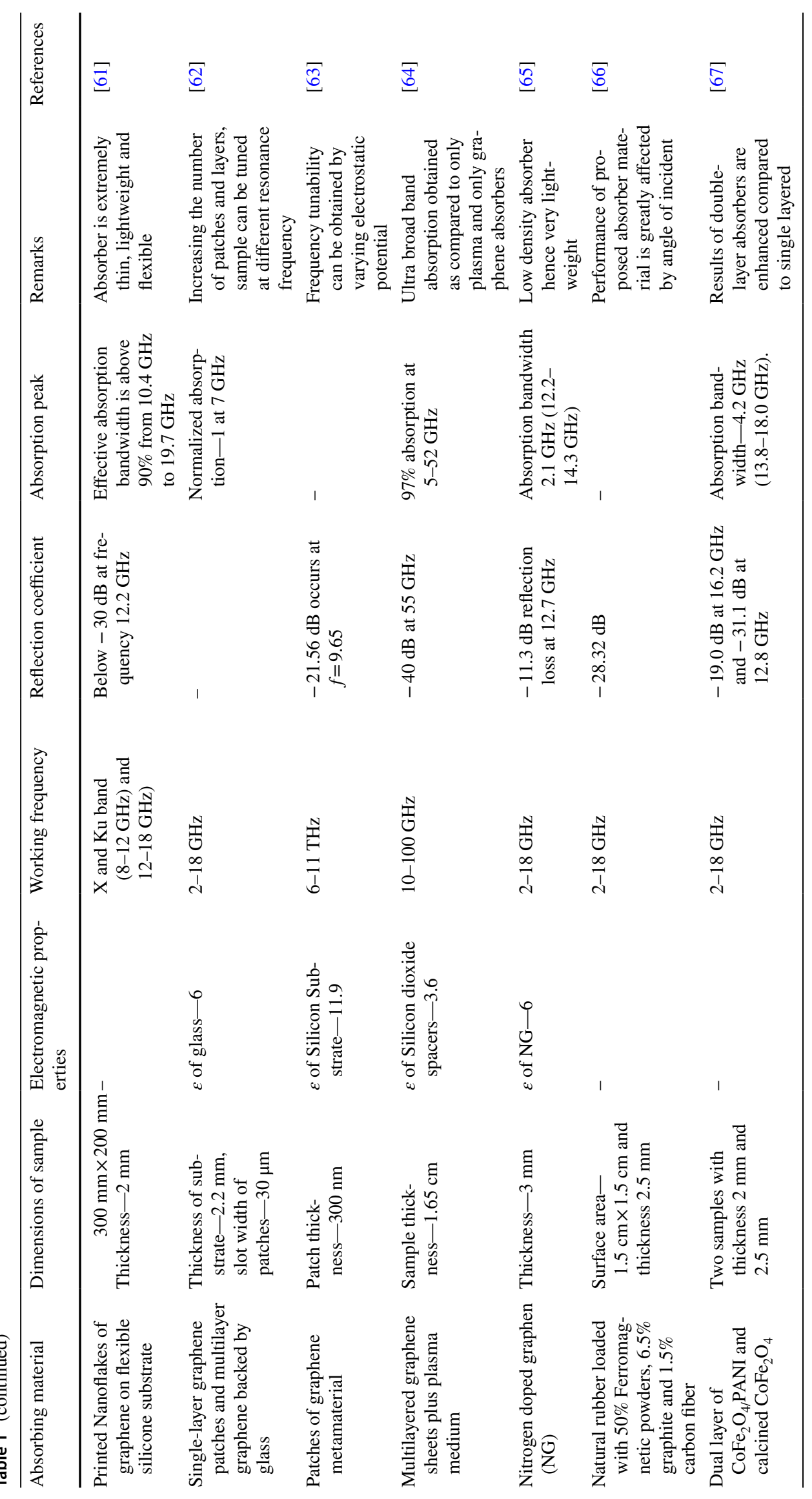


Kim et al. proposed a metamaterial-inspired absorbers adopting resistive trumpet structures which consists of trumpet-shaped resonator chip resistor on an FR4 substrate having permittivity 4.4 backed by a metallic plane. The dimension of the unit cell is $5.6 \mathrm{~mm} \times 5.6 \mathrm{~mm}$ with thickness $2.4 \mathrm{~mm}$, operates in $\mathrm{X}$ band $(8-12 \mathrm{GHz})$. From simulations, authors concluded that $99.5 \%$ absorption is obtained at $13.3 \mathrm{GHz}$ frequency. Due to pattern symmetry, the proposed model is independent to angle of incidence [70].

Kundu et al. presented the two-dimensional array of conductive crossed dipoles with lumped resistor elements on the top of a single-layer FR4 substrate, backed by continuous metallic layer, where crossed dipoles works as frequencyselective surface, whereas losses are provided by lumped elements thus offers the $10-\mathrm{dB}$ reflection reduction bandwidth of $70.7 \%(5.3-11.2 \mathrm{GHz})$ includes $\mathrm{C}$ and $\mathrm{X}$ bands. The authors used resistors in design to introduce losses which increases system cost. They proposed that instead of resistors, material with high tangent losses can serve the desired purpose [71].

Sood et al. low profile metamaterial microwave absorber composed of a periodic structure of microstrip bends etched on FR4 dielectric substrate having relative permittivity 4.4 and 0.02 as dielectric loss tangent. Dimension of unit cell is of 0.16 times of wavelength and thickness is $1 / 18$ times of lambda, especially designed for $\mathrm{X}$ band provides the $10 \mathrm{~dB}$ absorption bandwidth from 8.60 to $12.35 \mathrm{GHz}$. Authors have concluded that when length of structure is decreased, absorption frequencies increase and absorption level decreases; therefore, $4.2 \mathrm{~mm}$ is considered as optimized length having absorption level above $90 \%$ [72].

Hardiati et al. proposed microwave absorber with fabric form which consists of knitted metal wire having very small and thin structure mainly for $\mathrm{S}$ band ranging from 2.65 to $3.95 \mathrm{GHz}$. The metal fiber has the thickness of $164.32 \mu \mathrm{m}$, whereas the length and width of voids are $177.10 \mu \mathrm{m}$ and $477.35 \mu \mathrm{m}$. Authors measured the reflection coefficient of this absorber experimentally using vector network analyser (VNA) and concluded that the value of reflection loss is $-0.357 \mathrm{~dB}$ at $3.2 \mathrm{GHz}$ frequency [73].
Cheng et al. presented magnetic rubber plate metamaterial absorber having cross-shaped resonator structure backed by FR4 metallic substrate and metallic ground plane. Thickness of complete sample was $2 \mathrm{~mm}$ and authors suggested that it can be decreased to increase centre frequency peak between frequency range of 2-8 GHz. Authors experimentally demonstrated that absorber has $2.5 \mathrm{GHz}$ effective absorption bandwidth in frequency range of $2.5-5 \mathrm{GHz}$ and reflectance goes below $-15.5 \mathrm{~dB}$ at $3.5 \mathrm{GHz}$ frequency for sample thickness of $1.9 \mathrm{~mm}$ [74].

Al-Zoubi et al. presented a fabricating technique to enhance the performance of microwave absorbers using twodimensional array of circular cylinder dielectric resonators made by composite nanopowdered Fe20Ni8 material having relative permittivity in the range of 16-28 and relative permeability $1-1.8$ backed by perfect electric conductor ground plain. Initial radius, height, and lattice constant of each element of dielectric resonator array sets equal to $2.2 \mathrm{~mm}$, $5.0 \mathrm{~mm}$, and 5.7, respectively. By changing these three parameters, reflection loss peaks can effectively changed from one frequency to other within the band of 1-20 GHz. Model is designed and simulated using ANSYS HFSS (FEM based) and various reflection loss graphs by considering different parameter values are plotted.

Authors have concluded that a flat layer of nanopowdered $\mathrm{Fe}_{20} \mathrm{Ni}_{8}$ material with thickness of $5 \mathrm{~mm}$ backed by perfect electric conductor (PEC) shows reflection loss (RL) peak as low as $-50 \mathrm{~dB}$ and $3 \mathrm{GHz} 10-\mathrm{dB}$ bandwidth, whereas the same material when shaped into MA-CDR array, of height of $4 \mathrm{~mm}$ can achieve as low as $-50 \mathrm{~dB}$ RL peak and $12 \mathrm{GHz}$ 10-dB RL bandwidth. However, the performance as well as thickness can be improved using CDR structures with advanced materials [75].

Naser-Moghadasi et al. modified the performance of Jerusalem Cross metamaterial microwave absorber earlier proposed by [76] by adding the meandered load for Ku band. Authors have designed two prototypes. In the first prototype, Jerusalem Cross metamaterial microwave absorber is manufactured on FR-4 dielectric substrate having relative permittivity 4.4 , thickness is $1.6 \mathrm{~mm}$, and loss tangent is 0.02. Absorption properties of this prototype are investigated
Fig. 3 a, b Schematic of tapered hyperbolic metamaterial array and its unit cell [69]
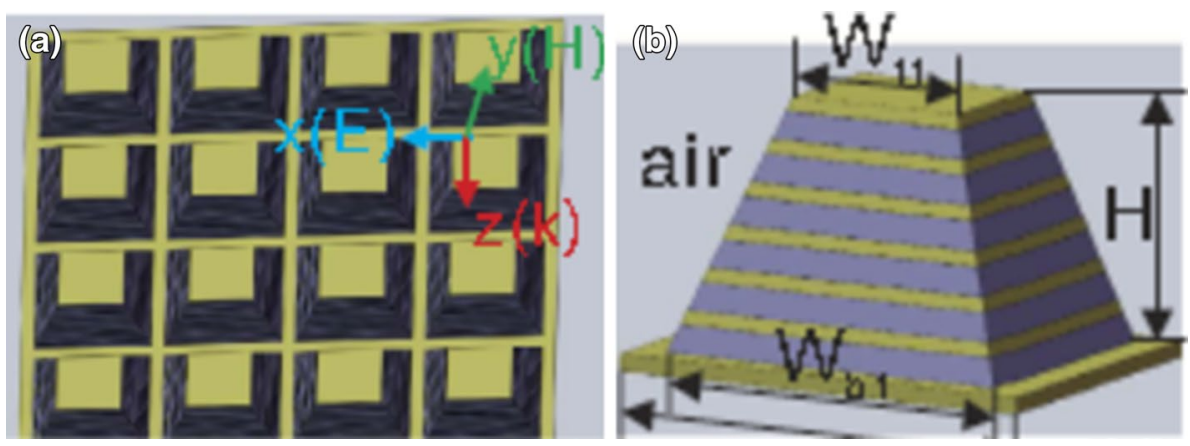


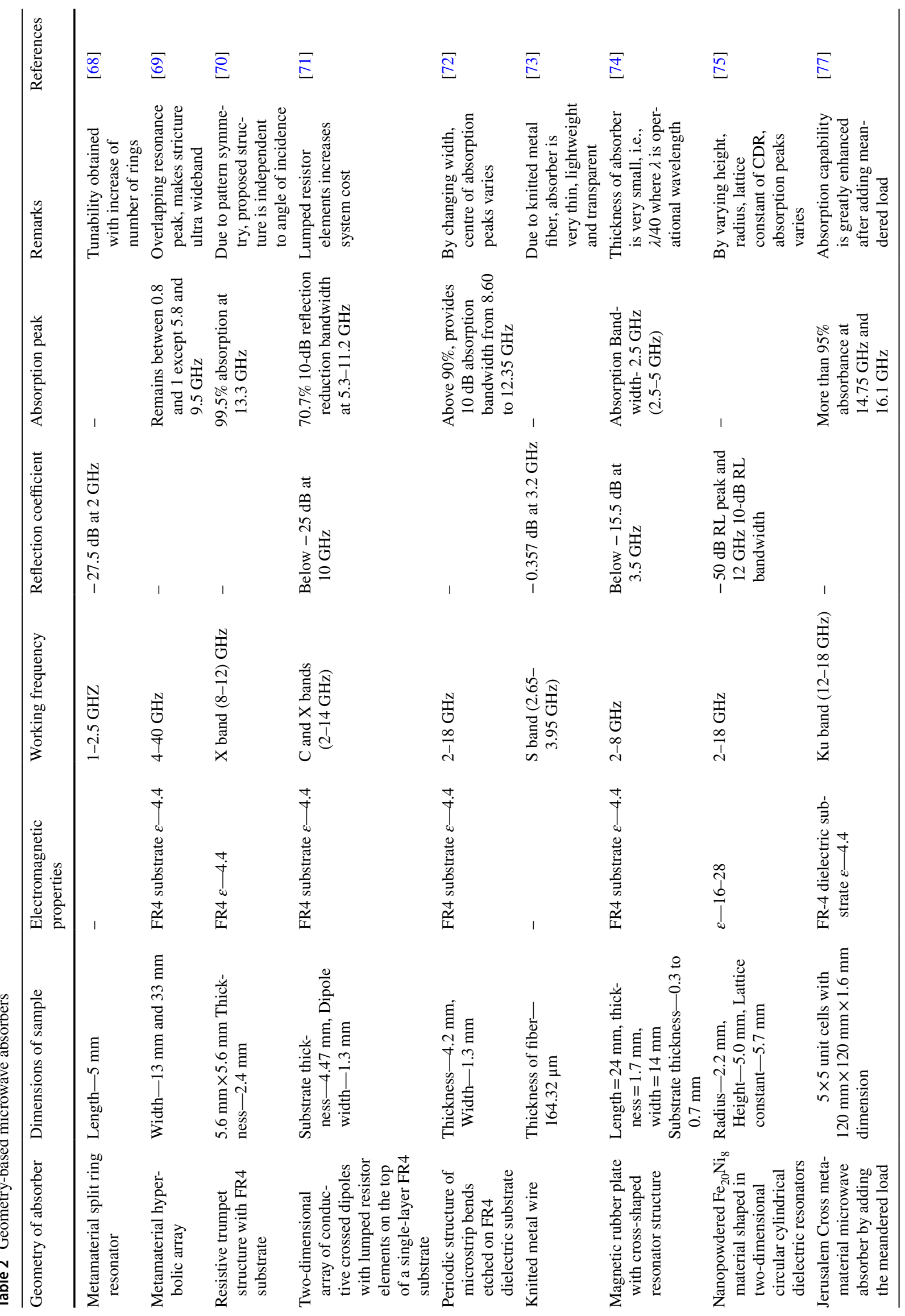


by performing simulation on CST. Performance of this structure is modified by adding two metallic layers of copper having thickness of $35 \mu \mathrm{m}$ to each unit cell. $5 \times 5$ unit cells are arranged to make $120 \mathrm{~mm} \times 120 \mathrm{~mm} \times 1.6 \mathrm{~mm}$ absorber structure.

Simulation results are compared with experimental results in which both prototypes are placed between two horn antennas with different radiation angles. Authors have concluded that by adding meandered load in symmetric form, new resonance appears in cross structure, and by controlling the width of loads, resonance are placed near to each other to make wider bandwidth [77] (Table 2).

From the above survey, it is analyzed that in almost all absorbers whether these are material based or structured based, the frequency of absorption lies between 1 and $20 \mathrm{GHz}$. Reason of this may be that most of the antennas and wireless systems have been developed and commercially used in this particular range; hence, more will be the pollution in this range. In addition, the absorbers used for stealth technology have to work in popular radar band (X and $\mathrm{Ku}$ band) which again lies in the same band. However, with the increasing use of wireless devices, frequency channels in microwave range are getting crowded; hence, authors shift their interest to nanosized antennas worked on terahertz frequency range [78] which give larger operational bandwidth as well as miniaturizing the size of device. Therefore, it becomes equally important to concentrate on nanomaterialbased absorbers worked in terahertz band which are able to provide electromagnetic shielding and eliminate wave pollution at terahertz range too $[79,80]$.

\section{Conclusion}

Microwave absorbers are currently in great demand on account of their application in suppressing electromagnetic pollution, sidelobe suppression in antenna array or in defence to reduce radar cross section. Particularly, nanomaterial-based absorbers are very small in size and can be used with integrated circuits to provide RF shielding to ICs hence extensively reviewed in this paper. With the development of testing equipments, it becomes easy to explore the properties of advanced nanomaterials as well as manufacturing metamaterials, which can make a thin, lightweight, tunable and transparent microwave absorber. When these materials are arranged in a particular geometric shape, performance in terms of absorption capabilities and bandwidth can be further enhanced. From this literature review, it can be concluded that by shaping an advanced material which either has high permittivity or permeability into an absorber compatible geometry, a model can be proposed which will able to meet the absorber requirements not only at gigahertz range but also on terahertz frequencies.
Acknowledgements This review paper is supported by Sant Longowal institute of Engineering and technology (SLIET), Longowal, Sangrur.

Open Access This article is distributed under the terms of the Creative Commons Attribution 4.0 International License (http://creativeco mmons.org/licenses/by/4.0/), which permits unrestricted use, distribution, and reproduction in any medium, provided you give appropriate credit to the original author(s) and the source, provide a link to the Creative Commons license, and indicate if changes were made.

\section{References}

1. Liu, Z., Bai, G., Huang, Y., Li, F., Ma, Y., Guo, T., He, X., Lin, X., Gao, H., Chen, Y.: Microwave absorption of single-walled carbon nanotubes/soluble cross-linked polyurethane composites. J. Phys. Chem. C 111, 37 (2007)

2. Liu, T., Pang, Y., Zhu, M., Kobayashi, S.: Microporous Co@CoO nanoparticles with superior microwave absorption properties. Nanoscale 6, 2447 (2014)

3. Wang, L., Huang, Y., Sun, X., Huang, H., Liu, P., Zong, M., Wang, Y.: Synthesis and microwave absorption enhancement of graphene@ $\mathrm{Fe}_{3} \mathrm{O}_{4} @ \mathrm{SiO}_{2} @ \mathrm{NiO}$ nanosheet hierarchical structures. Nanoscale 6, 3157 (2014)

4. Yin, X., Kong, L., Zhang, L., Cheng, L., Travitzky, N., Greil, P.: Electromagnetic properties of $\mathrm{Si}-\mathrm{C}-\mathrm{N}$ based ceramics and composites. Int. Mater. Rev. 59, 326 (2014)

5. Yan, D.X., Pang, H., Li, B., Vajtai, R., Xu, L., Ren, P.G., Wang, J.H., Li, Z.M.: Structured reduced graphene oxide/polymer composites for ultra-efficient electromagnetic interference shielding. Adv. Funct. Mater. 25, 559 (2015)

6. Sun, D., Zou, Q., Wang, Y., Wang, Y., Jiang, W., Li, F.: Controllable synthesis of porous $\mathrm{Fe}_{3} \mathrm{O}_{4} @ \mathrm{ZnO}$ sphere decorated graphene for extraordinary electromagnetic wave absorption. Nanoscale $\mathbf{6}$, $6557(2014)$

7. Zhang, X.-J., Wang, G.-S., Cao, W.-Q., Wei, Y.-Z., Liang, J.-F., Guo, L., Cao, M.-S.: Enhanced microwave absorption property of reduced graphene oxide ( $\mathrm{RGO})-\mathrm{MnFe}_{2} \mathrm{O}_{4}$ nanocomposites and polyvinylidene fluoride. ACS Appl. Mater. Interfaces 6, 7471 (2014)

8. van der Plas, G., Barel, A., Schweicher, E.: A spectral iteration technique for analysing scattering from circuit analog absorbers. IEEE Trans. Antennas Propag. 37, 1327 (1989)

9. Munk, B.A.: Frequency Selective Surfaces: Theory and Design. Wiley, New York (2000)

10. Chambers, B.: A smart radar absorber. Smart Mater. Struct. 8, 64 (1999)

11. Zhao, X., Zhang, Z., Wang, L., Xi, K., Cao, Q., Wang, D., Yang, Y., Du, Y.: Excellent microwave absorption property of graphenecoated Fe nanocomposites. Sci. Rep. 3, 3421 (2013)

12. Fan, Z., Luo, G., Zhang, Z., Zhou, L., Wei, F.: Electromagnetic and microwave absorbing properties of multi-walled carbon nanotubes/polymer composites. Mater. Sci. Eng. B 132, 85 (2006)

13. Oh, J.-H., Oh, K.-S., Kim, C.-G., Hong, C.-S.: Design of radar absorbing structures using glass/epoxy composite containing carbon black in X-band frequency ranges. Compos. Part B 35, 49 (2004)

14. Wang, C., Han, X., Xu, P., Zhang, X., Du, Y., Hu, S., Wang, J., Wang, X.: The electromagnetic property of chemically reduced graphene oxide and its application as microwave absorbing material. Appl. Phys. Lett. 98, 072906 (2011)

15. Fan, Y., Yang, H., Li, M., Zou, G.: Evaluation of the microwave absorption property of flake graphite. Mater. Chem. Phys. 115, 696 (2009) 
16. Cao, M.-S., Song, W.-L., Hou, Z.-L., Wen, B., Yuan, J.: The effects of temperature and frequency on the dielectric properties, electromagnetic interference shielding and microwaveabsorption of short carbon fiber/silica composites. Carbon 48, 788 (2010)

17. Ye, Q.W., Lin, H., Chen, X.Q., Yang, H.L.: A tunable metamaterial absorber made by micro-gaps structures. In: Proceedings of 2011 Cross Strait Quad-Regional Radio Science and Wireless Technology Conference, Harbin, China, vol. 234 (2011)

18. Lee, H.: Design of metamaterial absorber based on resonant magnetic inclusion. In: Proceedings of the 2012 International Symposium on Antennas and Propagation, Nagoya, Japan, vol. 1501 (2012)

19. Micheli, D., Apollo, C., Pastore, R., Marchetti, M.: X-band microwave characterization of carbon-based nanocomposite material, absorption capability comparison and RAS desing simulation. Compos. Sci. Technol. 70, 400 (2010)

20. Dombovari, A., Halonen, N., Sapi, A.: Moderate anisotropy in the electrical conductivity of bulk MWCNT/epoxy composites. Carbon 48, 1918 (2010)

21. Snoek, J.L.: Dispersion and absorption in magnetic ferrites at frequencies above one Mc/s. Physica 14(4), 207-217 (1948)

22. Ping, X., Xijiang, H., Maoju, W.: Synthesis and magnetic properties of $\mathrm{BaFe}_{12} \mathrm{O}_{19}$ hexaferrite nanoparticles by a reverse microemulsion technique. J. Phys. Chem. C 111, 5866 (2007)

23. Guohong, M., Na, C., Xifeng, P., Haigen, S., Mingyuan, G.: Preparation and microwave absorption properties of barium ferrite nanorods. Mater. Lett. 62, 840 (2008)

24. Sugimoto, S., Haga, K., Kagotani, T., Inomata, K.: Microwave absorption properties of Ba M-type ferrite prepared by a modified coprecipitation method. J. Magn. Magn. Mater. 290, 1188 (2005)

25. Wang, W., Guo, J.X., Long, C., Li, W., Guan, J.G.: Flaky carbonyl iron particles with both small grain size and low internal strain for broadband microwave absorption. J. Alloys Compd. 637, 106 (2015)

26. El Rhazi, M., Majid, S., Elbasri, M., Salih, F.E., Oularbi, L., Lafdi, K.: Recent Progress in Nanocomposites Based on Conducting Polymer-Application as Electrochemical Sensors. International Nano Materials, pp. 1-21. Springer, New York (2018)

27. Alkuh, M.S., Famili, M.H.N., Shirvan, M.M.M., Moeini, M.H.: The relationship between electromagnetic absorption properties and cell structure of poly(methyl methacrylate)/multi-walled carbon nanotube composite foams. Mater. Des. 100, 73 (2016)

28. Wang, T., Wang, P., Wang, Y., Qiao, L.: A broadband far-field microwave absorber with a sandwich structure. Mater. Des. 95, 486 (2016)

29. Yu, Z., Yao, Z., Zhang, N., Wang, Z., Li, C., Han, X., Wu, X., Jiang, Z.: Electric field induced synthesis of dendritic nanostructured a-Fe for electromagnetic absorption application. J. Mater. Chem. A 1(14), 4571 (2013)

30. He, C., Qiu, S., Wang, X., Liu, J., Luan, L., Liu, W., Itoh, M., Machida, K.: Facile synthesis of hollow porous cobalt spheres and their enhanced electromagnetic properties. J. Mater. Chem. 22, 22160 (2012)

31. Qiao, L., Han, X., Gao, B., Wang, J., Wen, F., Li, F.: Microwave absorption properties of the hierarchically branched Ni nanowire composites. J. Appl. Phys. 105, 053911 (2009)

32. Tong, G., Hu, Q., Wu, W., Li, W., Qian, H., Liang, Y.: Submicrometer-sized $\mathrm{NiO}$ octahedra facile one-pot solid synthesis, formation mechanism, and chemical conversion into Ni octahedra with excellent microwave-absorbing properties. J. Mater. Chem. 22, 17494 (2012)

33. Marwaha, A., Singh, G.R.: A review of metamaterials and its applications. Int. J. Eng. Trends Technol. (IJETT) 19(6), 305-310 (2015)
34. Kuo, F.-Y., Wang, P.-S., Chin, C.-Y., Hwang, R.-B.: Novel absorbers based on wideband antenna array for RCS reduction. Prog. Electromagn. Res. B 52, 237 (2013)

35. Song, N.-N., Ke, Y.-J., Yang, H.-T., Zhang, H., Zhang, X.-Q., Shen, B.-G., Cheng, Z.-H.: Integrating giant microwave absorption with magnetic refrigeration in one multifunctional intermetallic compound of $\mathrm{LaFe}_{11.6} \mathrm{Si}_{1.4} \mathrm{C}_{0.2} \mathrm{H}_{1.7}$. Sci. Rep. 3, 2291 (2013)

36. Zhang, L., Zhang, X., Zhang, G., Zhang, Z., Liu, S., Li, P., Liao, Q., Zhao, Y., Zhang, Y.: Investigation on the optimization, design and microwave absorption properties of reduced graphene oxide/ tetrapod-like ZnO composites. RSC Adv. 5, 10197 (2015)

37. Qin, X., Cheng, Y., Zhou, K., Huang, S., Hui, X.: Microwave absorbing properties of W-type hexaferrite $\mathrm{Ba}(\mathrm{MnZn})_{\mathrm{x}} \mathrm{Co}_{2(1-\mathrm{x})} \mathrm{F}$ $\mathrm{e}_{16} \mathrm{O}_{27}$. Sci. Res. J. Mater. Sci. Chem. Eng. 1, 8 (2013)

38. Liu, Y., Liu, X., Wang, X.: Double-layer microwave absorber based on $\mathrm{CoFe}_{2} \mathrm{O}_{4}$ ferrite and carbonyl iron composites. Elsevier J. Alloys Compd. 584, 249 (2013)

39. Li, W., Wei, J., Wang, W., Hu, D., Li, Y., Guan, J.: Ferrite-based metamaterial microwave absorber with absorption frequency magnetically tunable in a wide range. Elsevier Mater. Des. 110, 27 (2016)

40. Vinayasree, S., Soloman, M.A., Sunny, V., Mohanan, P., Kurian, P., Anantharaman, M.R.: A microwave absorber based on strontium ferrite-carbon black-nitrile rubber for $\mathrm{S}$ and $\mathrm{X}$-band applications. Elsevier Compos. Sci. Technol. 82, 69 (2013)

41. Teber, A., Cil, K., Yilmaz, T., Eraslan, B., Uysal, D., Abdul, G.S., Baykal, H., Bansal, R.: Manganese and zinc spinel ferrites blended with multi-walled carbon nanotubes as microwave absorbing materials. Aerospace 1, 1 (2017)

42. Gogoe, D.J., Bhattacharyya, N.S.: Flexible microwave absorber based on strontium ferrite-rubber composite for X-band applications. Int. J. Res. Eng. Technol. 6, 47 (2017)

43. Zhao, X., Zhang, Z., Wang, L., Xi, K., Cao, Q., Wang, D., Yang, Y., Youwei, D.: Excellent microwave absorption property of Graphene-coated Fe nanocomposites. Nat. Sci. Rep. 3, 1 (2013)

44. Campbell, S.D., Ziolkowski, R.W.: Lightweight, flexible, polarization-insensitive, highly absorbing meta-films. IEEE Trans. Antenna Propag. 61, 1191 (2013)

45. Fan, Y.N., Cheng, Y.Z., Deng, Y.M., Gong, R.Z.: Absorbing performance of ultrathin wide-band planar metamaterial absorber. In: Proceedings of the 2012 10th International Symposium on Antennas, Propagation and EM Theory, Xian, China, vol. 672 (2012)

46. Yoo, M., Lim, S.: Wideband metamaterial absorber using an RC layer. In: Proceedings of 2013 Asia-Pacific Microwave Conference, Seoul, Korea, vol. 1227 (2013)

47. Bhattacharya, P., Das, C.K.: Graphene and MWCNT: potential candidate for microwave absorbing materials. J. Mater. Sci. Res. 1, $126(2012)$

48. Zhang, D.-D., Zhao, D.-L., Zhang, J.-M., Bai, L.-Z.: Microwave absorbing property and complex permittivity and permeability of graphene-CdS nanocomposite. Elsevier J. Alloys Compd. 589, 378 (2013)

49. Batrakov, K., Kuzhir, P., Maksimenko, S., Paddubskaya, A., Voronovich, S., Lambin, P., Kaplas, T., Svirko, Y.: Flexible transparent graphene/polymer multilayers for efficient electromagnetic field absorption. Nat. Sci. Rep. 4, 1 (2014)

50. Barbosa, G.M., Mosso, M.M., Vilani, C., Larrud, D.R.G., Romani, E.C., Junior, F.L.: Graphene microwave absorber-transparent, lightweight, flexible, and cost-effective. Microw. Opt. Technol. Lett. 56, 560 (2014)

51. Wu, B., Tuncer, H.M., Naeem, M., Yang, B., Cole, M.T., Milne, W.I., Hao, Y.: Experimental demonstration of a transparent graphene millimetre wave absorber with $28 \%$ fractional bandwidth at $140 \mathrm{GHz}$. Nat. Sci. Rep. Electr. Electron. Eng. 4, 1 (2014) 
52. Savi, P., Miscuglio, M., Giorcelli, M., Tagliaferro, A.: Analysis of microwave absorbing properties of epoxy MWCNT composites. Prog. Electromagn. Res. Lett. 44, 63 (2014)

53. Bian, W., Tuncer, H.M., Katsounaros, A., Weiping, W., Cole, M.T., Ying, K., Zhang, L., Milne, W.I., Hao, Y.: Microwave absorption and radiation from large-area multilayer CVD graphene. Carbon 77, 814 (2014). (Elsevier Ltd)

54. Balci, O., Polat, E.O., Kakenov, N., Kocabas, C.: Graphene-enabled electrically switchable radar-absorbing surfaces. Nat. Commun. 7628, 1 (2015). (Macmillan Publishers Limited.)

55. Xin, G., Da-Wei, H., Yong-Sheng, W., Wen, Z., Yi-Kang, Z., Shu-Lei, L.: Synthesis and microwave absorption properties of graphene-oxide(GO)/polyaniline nanocomposite with $\mathrm{Fe}_{3} \mathrm{O}_{4}$ particles. Chin. Phys. B 24, 1 (2015)

56. Zhang, Y., Huang, Y., Zhang, T., Chang, H., Xiao, P., Chen, H., Huang, Z., Chen, Y.: Broadband and tunable high-performance microwave absorption of an ultralight and highly compressible graphene foam. Adv. Mater. 2015, 1 (2015). (WILEY-VCH Verlag GmbH \& Co. KGaA, Weinheim)

57. Das, S., Nayak, G.C., Sahu, S.K., Oraon, R.: Development of $\mathrm{FeCoB} /$ graphene oxide based microwave absorbing materials for X-band region. J. Magn. Magn. Mater. 384, 224 (2015). (Elsevier)

58. Luo, J., Shen, P., Yao, W., Jiang, C., Xu, J.: Synthesis, characterization, and microwave absorption properties of reduced graphene oxide/strontium ferrite/polyaniline nanocomposites. Nanoscale Res. Lett. A Springer Open J. 11, 1 (2016)

59. Yi, D., Wei, X., Xu, Y.: Experimental demonstration of transparent microwave absorber based on graphene. IEEE Trans. Microw. Theory Tech. 16, 1 (2016)

60. Rubrice, K., Castel, X., Himdi, M., Parneix, P.: Dielectric characteristics and microwave absorption of graphene composite materials. J. Mater. 9, 1 (2016)

61. Huang, X., Pan, K., Zhirun, H.: Experimental demonstration of printed graphene nano-flakes enabled flexible and conformable wideband radar absorbers. Nat. Sci. Rep. 6, 1 (2016)

62. Yi, D., Wei, X.-C., Xu, Y.-L.: Tunable microwave absorber based on patterned graphene. IEEE Trans. Microw. Theory Tech. (2017). https://doi.org/10.1109/TMTT.2017.2678501

63. Xiong, H., Tang, M.-C., Li, M., Li, D., Jiang, Y.-N.: Equivalent circuit method analysis of graphene-metamaterial (GM) absorber. Plasmonics 6, 1 (2017). (Springer)

64. Rahmanzadeh, M., Rajabalipanah, H., Abdolali, A.: Analytical investigation of ultrabroadband plasma-graphene radar absorbing structures. IEEE Trans. Plasma Sci. 45, 945 (2017)

65. Heydari, F., Afghahi, S.S.S., Manteghian, M., Taghizadeh, M.J.: Nanosized amorphous ( $\mathrm{Co}, \mathrm{Fe}$ ) oxide particles decorated PANICNT: facile synthesis, characterization, magnetic, electromagnetic properties and their application. Int. Nano Lett. 7(275), 275-283 (2017). (Springer)

66. El-Hakim, H.A., Mahmoud, K.R., Abdelaziz, A.A.: Design of compact double-layer microwave absorber for X-Ku bands using genetic algorithm. Prog. Electromagn. Res. B. 65, 157 (2016)

67. Yewen, X., Shen, G., Hongyan, W., Liu, B., Fang, X., Zhang, D., Zhu, J.: Double-layer microwave absorber based on nanocrystalline $\mathrm{CoFe}_{2} \mathrm{O}_{4}$ and $\mathrm{CoFe}_{2} \mathrm{O}_{4} / \mathrm{PANI}$ multi-core/shell composites. Mater. Sci. Pol. 35, 94 (2017)

68. Bilotti, F., Toscano, A., Alici, K.B., Ozbay, E., Vegni, L.: Design of miniaturized narrowband absorbers based on resonant-magnetic inclusion. IEEE Trans. Electromagn. Compat. 53, 63 (2011)

69. Yin, X., Long, C., Li, J., Zhu, H., Chen, L., Guan, J., Li, X.: Ultrawideband microwave absorber by connecting multiple absorption bands of two different sized hyperbolic metamaterial waveguide arrays. Nat. Sci. Rep. 5, 1 (2015)

70. Kim, B.-K., Lee, B.: Design of metamaterial-inspired wideband absorber at X-band adopting trumpet structures. J. Electromagn. Eng. Sci. 14, 314 (2014)

71. Kundu, D., Mohan, A., Chakrabarty, A.: Single-layer wideband microwave absorber using array of crossed dipoles. IEEE Antennas Wirel. Propag. Lett. 15, 1589 (2016)

72. Sood, D., Tripathi, C.C.: A Wideband ultrathin low profile metamaterial microwave absorber. Microw. Opt. Technol. Lett. 57, $2723(2015)$

73. Hardiati, S., Setiawan, A., Santiko, A.B., Mahmudin, D., Wijayanto, Y.: Performance of microwave absorbers with fabric form in S-band operational frequency. In: 2016 IEEE International Conference on Radar, Antenna, Microwave, Electronics, and Telecommunications, vol. 16, p. 67 (2016)

74. Cheng, Y., He, B., Zhao, J., Gong, R.: Ultra-thin low-frequency broadband microwave absorber based on magnetic medium and metamaterial. J. Electron. Mater. 46, 1293 (2017)

75. Al-Zoubi, O.H., Naseem, H.: Enhancing the performance of the microwave absorbing materials by using dielectric resonator arrays. Hindawi Model. Simul. Eng. 2017, 1 (2017)

76. Lu, L., Qu, S., Ma, H., Yu, F., Xia, S., Xu, Z., Bai, P.: A polarization-independent wide-angle dual directional absorption metamaterials absorber. Prog. Electromagn. Res. 27, 191 (2012)

77. Naser-Moghadasia, M., Niaa, A.Z., Toolabia, M., Heydari, S.: Microwave metamaterial absorber based on Jerusalem Cross with meandered load for bandwidth enhancement. Optik 140, 515 (2017). (Elsevier GmbH)

78. Zhang, L., Yu, X., Hu, H., Li, Y., Wu, M., Wang, Z., Li, G., Sun, Z., Chen, C.: Facile synthesis of iron oxides/reduced graphene oxide composites-application for electromagnetic wave absorption at high temperature. Sci. Rep. 5, 9298 (2015)

79. Li, N., Huang, Y., Du, F., He, X., Lin, X., Gao, H., Ma, Y., Li, F., Chen, Y., Eklund, P.C.: Electromagnetic interference (EMI) shielding of single-walled carbon nanotube epoxy composites. Nano Lett. 6(6), 1141 (2006)

80. Liang, J., Wang, Y., Huang, Y., Ma, Y., Liu, Z., Cai, J., Zhang, C., Gao, H., Chen, Y.: Electromagnetic interference shielding of graphene/epoxy composites. Carbon 47(3), 922 (2009)

Publisher's Note Springer Nature remains neutral with regard to jurisdictional claims in published maps and institutional affiliations. 